\title{
KINETICS AND MECHANISM OF THE EARLY STAGES OF THE VOLTAMMETRIC ELECTROOXIDATION OF CARBON MONOXIDE PREADSORBED ON POLYCRYSTALLINE PLATINUM IN ACID ELECTROLYTE
}

\author{
S A. BILMES and A.J. ARVIA \\ Instututo de Investigactones Fisicoquimicas Teoricas y Aplicadas. INIFT.4. Casilla de Correo 16. Sucursal 4. \\ 1900 La Plata (Argentma)
}

(Received 11 th April 1985; in revised form 13th August 1985)

\begin{abstract}
The first stages of the electrooxidation of $\mathrm{CO}$ previously adsorbed on polycrystalline $\mathrm{Pt}$ in $1 \mathrm{M} \mathrm{HClO}_{4}$ at $25^{\circ} \mathrm{C}$ were investigated by means of the triangularly modulated triangular potental sweep technique. Runs were made with a Pt surface covered ether partially or completely with adsorbed CO over a wide range of frequency and amplitude of the modulating signal Reactions between the strongly and the weakly bonded adsorbed oxygen-containing adsorbed species with the linear and the bridge forms of adsorbed $\mathrm{CO}$ were followed via the voltammetric measurements. The kınetics of the various possible processes are discussed in terms of previous results on the voltammetric electrooxidation of adsorbed CO and on the early stages of $\mathrm{O}$-electroadsorption on $\mathrm{Pt}$. $\mathrm{CO}$ adsorption on Pt produces a change in the apparent electrode capacity which is interpreted in terms of the structure of the inner part of the electrical double layer.
\end{abstract}

\section{INTRODUCTION}

The electrooxidation of $\mathrm{CO}$ on $\mathrm{Pt}$ electrodes in acid solutions is a complex electrocatalytic process which involves the participation of several adsorbed intermediates, namely different $\mathrm{CO}$ species and those resulting from the upd discharge of water [1-9]. For slow voltammetric sweeps, the electrooxidation occurs at relatively low potentials when CO readsorption is avoided [4]. Otherwise, when the Pt surface is covered by oxygen-containing species the reaction takes place at higher positive potentials and, under certain conditions. becomes diffusion-controlled [10]. A different situation arises when the electrooxidation involves $\mathrm{CO}$ previously adsorbed on $\mathrm{Pt}$. This reaction, which is of interest because of its close relation to the electrooxidation of poisons formed during the electrooxidation of organic fuels, occurs at potentials where electroadsorbed oxygen-containing species are produced from water. This voltammetric electrooxidation reaction appears as a complex irreversible electrocatalytic process which depends on the electrolyte composition, the crystallographic characteristics of $\mathrm{Pt}$ and on temperature [11-13]. The current transients for 
this reaction are consistent with a reactant pair mechanism [3] where the heterogeneous chemical reaction between adsorbed $\mathrm{CO}$ and the surface oxygen-containing species takes place at the edge of growing two-dimensional islands of the platinum oxide [5]. The proper number of adsorbed reactants offers, in principle, various alternative reactions as initial stages of the electrooxidation of $\mathrm{CO}$ previously adsorbed on Pt. It is well established that there is a multiplicity of voltammetric peaks associated with $O$ electroadsorptions $[14,15]$ and that adsorbed $C O$ itself involves a linear and a bridge structure on polycrystalline $\mathrm{Pt}[3,9,16,17]$.

This work furnishes new data related to possible reactions entering the reactant pair mechanism. For this purpose the electrooxidation of $\mathrm{CO}$ previously adsorbed on polycrystalline $\mathrm{Pt}$ was carried out in the potential range where oxygen-containing adsorbed species are produced, by using relatively fast voltammetric sweep rates. The electrochemical characteristics of the reaction intermediates were followed by means of triangularly modulated voltammetry, which allows fast quasi-reversible pseudo-capacitive processes [18-20] to be detected when proper time windows are used. Working conditions were chosen carefully to avoid any influence of $\mathrm{CO}$ readsorption during the voltammetric runs [3,9].

\section{EXPERIMENTAL}

Runs were made at $25^{\circ} \mathrm{C}$ in a conventional three-compartment glass electrolytic cell. The working electrode consisted of a polycrystalline Pt wire (Johnson Matthey Chem. Co.) of $0.471 \mathrm{~cm}^{2}$ area and roughness factor of 1.6 , which was treated in the following way: (i) polishing with $0.3 \mu \mathrm{m}$ alumina suspension in water; (ii) immersion in hot $98 \% \mathrm{H}_{2} \mathrm{SO}_{4}$; (iii) rinsing first in boiling water which had been distilled three times and then in water vapour at $100^{\circ} \mathrm{C}$ to eliminate traces of sulphuric acid. The counter-electrode was a $\mathrm{Pt}$ wire spiral of large area. $\mathrm{A} \mathrm{Hg} / \mathrm{Hg}_{2} \mathrm{SO}_{4} / \mathrm{H}_{2} \mathrm{SO}_{4}$ reference electrode was used. This electrode was adequately shielded to avoid ionic diffusion from the reference electrode to the solution in the working electrode compartment. The potentials in the text are referred to the SHE.

A $1 M \mathrm{HClO}_{4}$ solution, prepared from $70 \% \mathrm{HClO}_{4}$ (Merck p.a.) and triply distilled water, was used as the electrolyte having a relatively small influence on anion adsorption. The electrolyte was used either under $\mathrm{N}_{2}$ saturation (blank runs) or under $\mathrm{CO}$ saturation at a pressure of $1 \mathrm{~atm}$.

The first part of the potential perturbation programme (Fig. 1) consisted of a number of repetitive triangular potential scans (RTPS) between $E_{\mathrm{\iota .c}}=-0.03 \mathrm{~V}$ and $E_{\checkmark, \mathrm{a}}=1.4 \mathrm{~V}$ at $10 \mathrm{~V} / \mathrm{s}$ in order to obtain a reproducible and stable voltammogram. This was followed by a potential step at $E_{\mathrm{s}}$ during the time $\tau$, for $\mathrm{CO}$ adsorption from the electrolyte solution on the Pt electrode. The value of $E$, was fixed at 0.38 $\mathrm{V}$, a potential at which there was practically no interference of either $\mathrm{H}$ or $\mathrm{O}$ adatoms on Pt. The values of $\tau$ covered the $0-20 \mathrm{~s}$ range so that $\mathrm{CO}$ coverages in the range $0-1$ were obtained [9]. Then, the electrode was subjected to a linear potential sweep guide from $E_{3}$ up to $E_{\varsigma, a}$ at the potential sweep rate $v_{g}$. which was triangularly modulated (IMTPS). The frequency of the modulating signal is given 


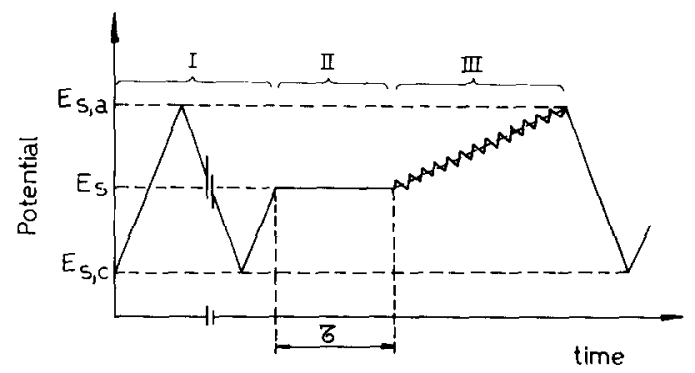

Fig. 1. Potential-time programme. (I) RTPS pretreatment at $10 \mathrm{~V} / \mathrm{s}$ : (II) $\mathrm{CO}$ adsorption period durıng time $\tau$; (III) voltammetric recording as shown in Figs 2, 4 and 5.

by the ratio $v_{\mathrm{m}} / 2 A_{\mathrm{m}}$, where $v_{\mathrm{m}}$ is the potential sweep rate in $\mathrm{V} / \mathrm{s}$ and $A_{\mathrm{m}}$ is the amplitude of the modulating signal in V. TMTPS parameters were set as follows: $v_{\mathrm{g}}=1 \mathrm{~V} / \mathrm{s}: 33 \mathrm{~V} / \mathrm{s} \leqq v_{\mathrm{m}} \leqq 333 \mathrm{~V} / \mathrm{s}$ and $20 \mathrm{mV} \leqq A_{\mathrm{m}} \leqq 200 \mathrm{mV}$. The value of $v_{\mathrm{g}}$ was the lowest one compatible with negligible readsorption of CO during the voltammetric run. The TMTPS voltammograms run in the positive direction were immediately followed by a single linear potential scan in the reverse direction at $v=10 \mathrm{~V} / \mathrm{s}$.

Experiments were carried out with two Tacussel function generators (GSATP) coupled to a fast rise time potentiostat (Tacussel PIT 20-2X). The complex voltammograms were displayed on an oscilloscope screen. Further details of the TMTPS technique are given in refs. 18 and 19.

RESULTS

Voltammetric runs in the absence of $\mathrm{CO}$

The TMTPS voltammograms of polycrystalline Pt reported in the literature in 0.5 $M \mathrm{H}_{2} \mathrm{SO}_{4}$ [18] show that the initial stage of $\mathrm{O}$ electroadsorption is a reversible process. These voltammograms depend on $v_{\mathrm{g}}, v_{\mathrm{m}}, A_{\mathrm{m}}$ and the electrolyte composition. Therefore, the TMTPS voltammograms of $\mathrm{Pt}$ in $1 M \mathrm{HClO}_{4}$ were run under exactly the same conditions used later in the presence of $\mathrm{CO}$ adsorbed on $\mathrm{Pt}$.

The TMTPS voltammograms run in $1 M \mathrm{HClO}_{4}$ in the absence of adsorbed $\mathrm{CO}$, for $v_{\mathrm{g}}=1 \mathrm{~V} / \mathrm{s}, v_{\mathrm{m}}=33 \mathrm{~V} / \mathrm{s}$ and $A_{\mathrm{m}}=20 \mathrm{mV}$ (Fig. 2), show a non-faradaic charge which is nearly constant in the $0.4-0.6 \mathrm{~V}$ range (the double-layer region) and three relatively fast conjugated pseudocapacitive contributions, namely one with well-defined anodic (Ia) (ca. $0.84 \mathrm{~V}$ ) and cathodic (Ic) (ca. $0.80 \mathrm{~V}$ ) current peaks and another two more poorly defined, whose conjugated pair of current peaks are at ca. $0.98 \mathrm{~V}$ (peak II) and ca. $1.27 \mathrm{~V}$ (peak III), respectively. These current peaks are related to conjugated surface processes occurring in the early stages of upd discharge of water yielding adsorbed $\mathrm{OH}$ and reversible adsorbed $\mathrm{O}$ species on a bare $\mathrm{Pt}$ 


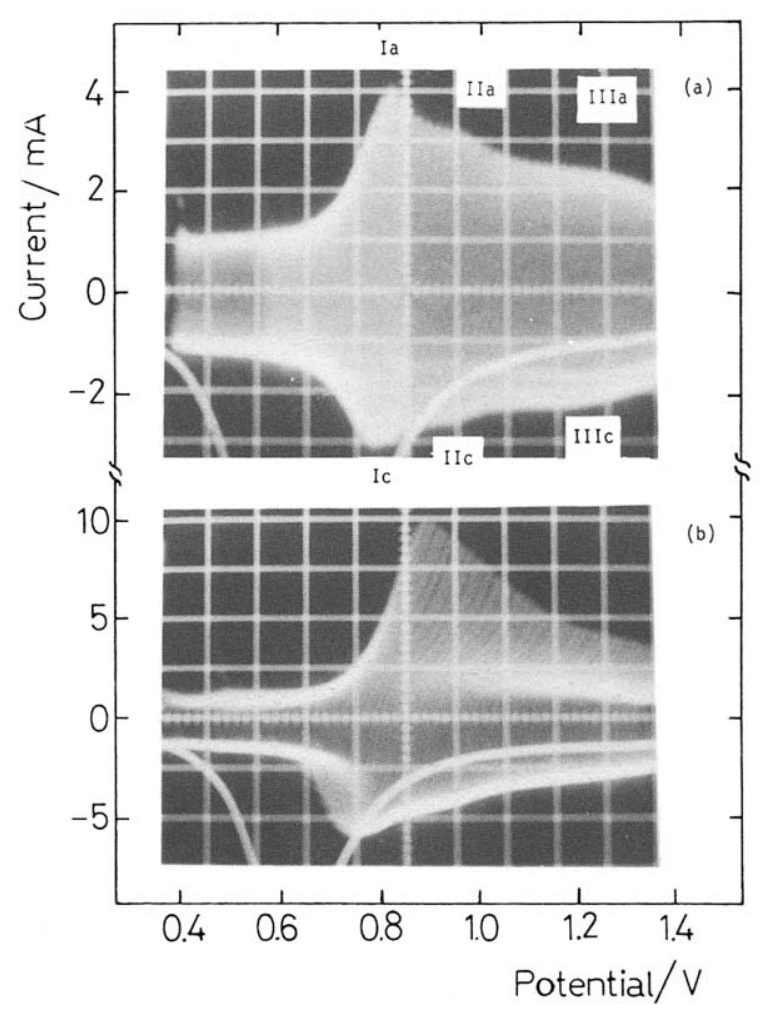

Fig. 2. TMTPS profiles run from negative to positive potential obtained at $\theta_{\mathrm{c} O}=0, v_{\mathrm{g}}=1 \mathrm{~V} / \mathrm{s} . v_{\mathrm{m}}=33$ $\mathrm{V} / \mathrm{s}$, and $A_{\mathrm{m}}=20(\mathrm{a})$ and $200 \mathrm{mV}(\mathrm{b})$.

surface site as represented by the following formal reactions $[14,15,18-20]$ :

$$
\begin{aligned}
& \mathrm{Pt}+\mathrm{H}_{2} \mathrm{O} \rightleftarrows \mathrm{Pt}(\mathrm{OH})+\mathrm{H}^{+}+e^{-} \\
& \mathrm{Pt}(\mathrm{OH}) \rightleftarrows \mathrm{Pt}(\mathrm{O})^{*}+\mathrm{H}^{+}+e^{-}
\end{aligned}
$$

where the parentheses denote adsorbed species and the asterisk an active adsorbed oxygen atom which, during the time the potential perturbation lasts, is unable to participate in ageing processes [21,22].

The voltammetric anodic charge, $Q_{\mathrm{d}}$, in Fig. $2 \mathrm{a}$ is practically equal to the corresponding cathodic charge, $Q_{c}$, as is expected for a reversible system under a low $A_{\mathrm{m}}$ value [19]. The value of $Q_{\mathrm{a}}\left(50 \mu \mathrm{C} / \mathrm{cm}^{2}\right)$. however, is only a fraction of that expected for an O-electroadsorbed monolayer on polycrystalline Pt. As $A_{\mathrm{n}}$ increases, peaks Ia and Ic move in the positive and in the negative direction, respectively, whereas peak IIc apparently remains at the same potential (Fig. 2b). In this case, peak Ia tends towards a greater overlapping with peak IIa, and peak IIc becomes a shoulder of peak Ic. The gradual increase in $A_{\mathrm{m}}$ allows the more irreversible electrochemical processes occurring at higher potentials to be picked up. 


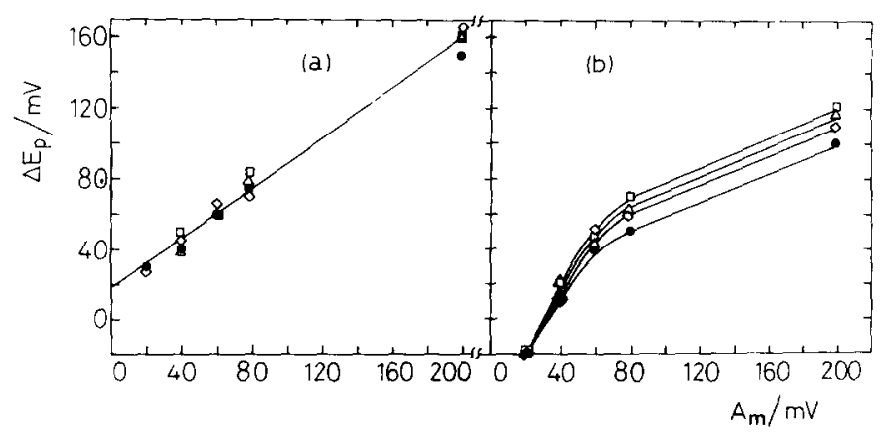

Fig. 3. Potential difference, $\Delta E_{n}$, between peaks Ia and Ic obtained for different values of $v_{m}$ as a function of $A_{\mathrm{m} ;} ; v_{\mathrm{g}}=1 \mathrm{~V} / \mathrm{s}$. (a) $\theta_{\mathrm{c}(\mathrm{l}}=0 ;$ (b) $\theta_{\mathrm{co}}=0.52 . v_{\mathrm{m}}=33(\bullet), 50(\diamond), 75(\Delta)$ and $100 \mathrm{~V} / \mathrm{s}(\square)$

Consequently, the peak multiplicity spreads out, the overall voltammetric response becomes more irreversible, the difference between the anodic and cathodic charges of each modulating cycle incrcases, and the difference, $\Delta E_{\mathrm{p}}$, between the potentials of peaks Ia and Ic increases linearly with $A_{\mathrm{m}}$, independent of $t_{\mathrm{m}}$, as predicted by TMTPS theory [19] (Fig. 3a). It is also noticed that as $A_{\mathrm{m}}$ increases, the $E / I$ display of each modulating cycle shows different $\Delta I / \Delta E$ slopes associated with determined potential ranges (time windows). This indicates the occurrence of coupled chemical and electrochemical surface processes [19].

\section{Voltammetric runs with CO previously adsorbed on Pt}

The voltammetric electrooxidation of $\mathrm{CO}$ preadsorbed on $\mathrm{Pt}$ in $1 \mathrm{M} \mathrm{HClO}_{4}$ was performed at two degrees of surface coverage, namely $\theta_{c \Omega}=0.52$ and $\theta_{c \Omega}=1$. CO adsorption was realized from $1 \mathrm{MHClO}_{4}$ under $\mathrm{CO}$ saturation by holding the electrode at $E_{\mathrm{s}}=0.38 \mathrm{~V}$ for $\tau_{1}=3.6 \mathrm{~s}$ for $\theta_{C O}=0.52$ and for $\tau_{2}=20 \mathrm{~s}$ for $\theta_{C O}=1$. The $E$, and $\tau$ values were selected from previous investigations on $C O$ electrooxidation in acid electrolytes $[9,13]$.

A multiplicity of anodic current peaks was previously reported $[9,13]$ in the electrooxidation of adsorbed $\mathrm{CO}$ on $\mathrm{Pt}$ in acid when $0<\theta_{\mathrm{CO}}<1$. This result was assigned to the presence of at least two energetically distinguishable $\mathrm{CO}$ reactants on the $\mathrm{Pt}$ surfaces, namely a bridged $\mathrm{CO}-\mathrm{Pt}$ structure, $(\mathrm{CO})_{\mathrm{B}}$, and a linear $\mathrm{CO}-\mathrm{Pt}$ structure $(\mathrm{CO})_{\mathrm{L}}$. The electrooxidation potential range of $(\mathrm{CO})_{\mathrm{L}}$ is more positive than that of $(\mathrm{CO})_{B}$. As $\theta_{C O} \rightarrow 1$, only $(\mathrm{CO})_{L}$ is found since each adsorbed $\mathrm{CO}$ molecule is bonded to a single surface $\mathrm{Pt}$ atom [9].

The surface concentration ratio of $(\mathrm{CO})_{\mathrm{B}}$ and $(\mathrm{CO})_{\mathrm{L}}$ can be estimated from previously published kinetic data [9]. For $\theta_{\mathrm{CO}}=0.52$, one obtains $\theta_{\mathrm{CO}}^{\mathrm{B}} \simeq 0.34$ and $\theta_{C O}^{!}=0.18$, while for $\theta_{C O}=1, \theta_{C O}^{\mathrm{R}}=0$ and $\theta_{C O}^{\mathrm{l}}=1$ are obtained.

The TMTPS voltammograms run in the presence of adsorbed CO (Fig. 4) for a constant $v_{\mathrm{g}}$ also depend on $v_{\mathrm{m}}, A_{\mathrm{m}}$ and. in addition, on $\theta_{\mathrm{CO}}$. For $\theta_{\mathrm{CO}}=0.52$ (Fig. $4 a$ ), the double-layer region extends into the $0.39-0.70 \mathrm{~V}$ range and the irreversible 


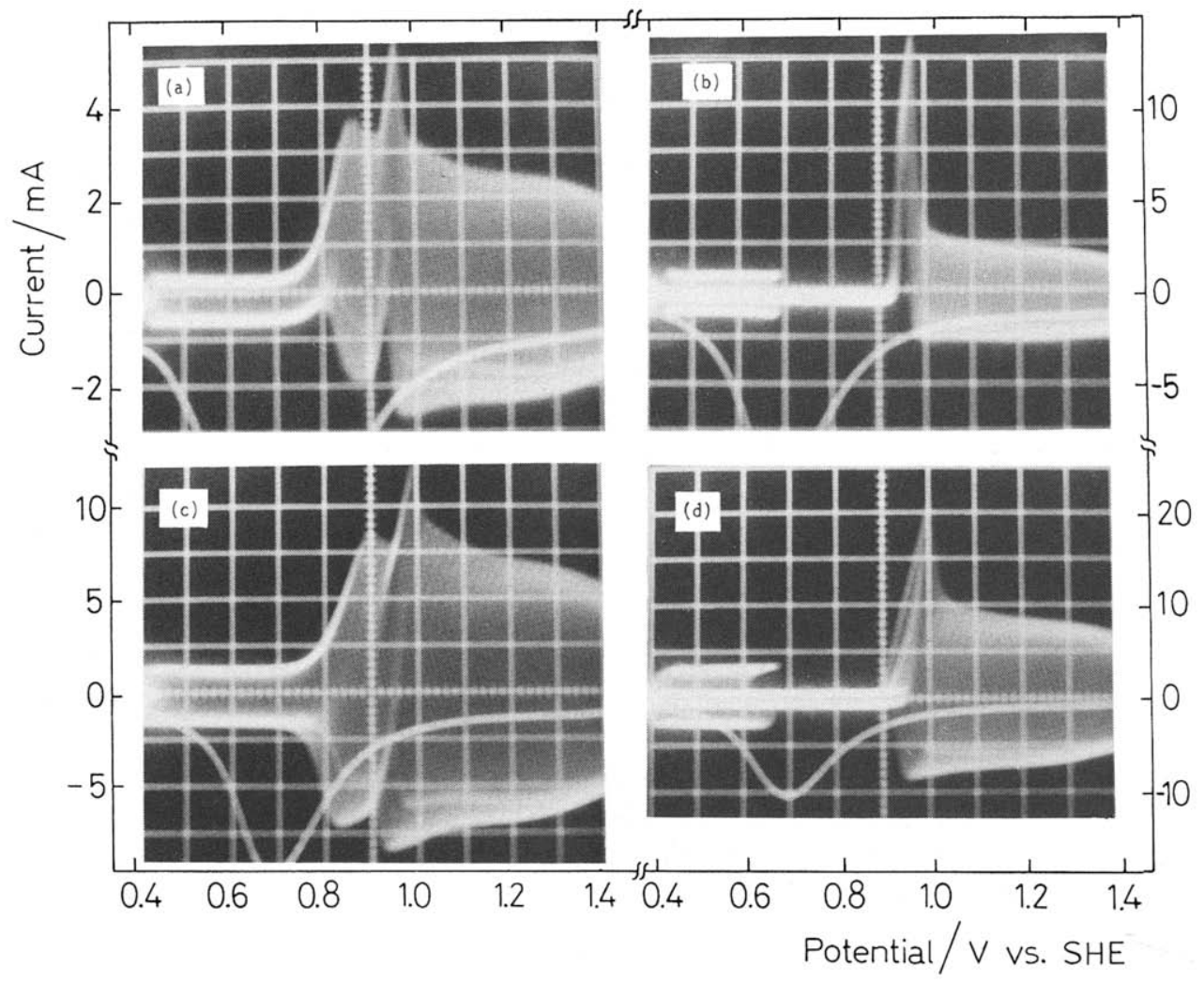

Fig. 4. TMTPS profiles obtaned after adsorption of $\mathrm{CO}$ for $\theta_{\mathrm{CO}}=0.52(\mathrm{a}, \mathrm{c})$ and $\theta_{\mathrm{CO}}=1(\mathrm{~b}, \mathrm{~d}) . v_{\mathrm{g}}=1$ $\mathrm{V} / \mathrm{s}$; (a.b) $A_{\mathrm{m}}=20 \mathrm{mV}, v_{\mathrm{m}}=33 \mathrm{~V} / \mathrm{s} ;$ (c,d) $A_{\mathrm{m}}=80 \mathrm{mV}, v_{\mathrm{m}}=100 \mathrm{~V} / \mathrm{s}$.

electrooxidation of adsorbed $\mathrm{CO}$ begins at a potential which practically coincides with the threshold potential of reaction (1). The irreversible process which is assigned to the first stage of $(\mathrm{CO})_{B}$ electrooxidation is associated with the disappearance of the reversible peaks of reaction (1). This is clear evidence that adsorbed $\mathrm{OH}$ participates as an intermediate in the $(\mathrm{CO})_{\mathrm{B}}$ electrooxidation. When part of the adsorbed $(\mathrm{CO})_{\mathrm{B}}$ has been oxidized the cathodic peak at ca. $0.85 \mathrm{~V}(\mathrm{Ic})$, which characterizes reaction (1), starts to appear. Later, as the potential of the guide ramp enters the 0.95-1.05 $\mathrm{V}$ range the voltammogram shows another irreversible anodic current associated with $(\mathrm{CO})_{\mathrm{L}}$ electrooxidation, and finally, at potentials higher than $1.05 \mathrm{~V}$, as the electrooxidation of adsorbed $\mathrm{CO}$ is completed, the TMTPS voltammogram coincides with that for $\mathrm{Pt}$ in $1 \mathrm{MHClO}_{4}$ in the absence of adsorbed $\mathrm{CO}$.

When the TMTPS voltammograms for $\theta_{C O}=0.52$ imply increasing values of $A_{\mathrm{m}}$ (Fig. 4c), other possible irreversible steps following the first stage of $(\mathrm{CO})_{\mathrm{B}}$ electrooxidation are detected. In this case, the current corresponding to the first electrooxidation stage overlaps with peak la related to the upd electrooxidation of water. 
This overlapping is revealed clearly through the dependence of $\Delta E_{\mathrm{p}}$ on $A_{\mathrm{m}}$ (Fig. 3b) at low $A_{\mathrm{m}}$. The negative values of $\Delta E_{\mathrm{p}}$ resulting at $A_{\mathrm{n}}=20 \mathrm{mV}$ indicate that when $\left(\mathrm{CO}_{\mathrm{B}}\right)$ electrooxidation is completed, the reversible electroadsorbed $\mathrm{OH}$ intermediates are formed during the modulated cycling at more positive potentials and are detected in the potential range which characterizes reaction (1).

The TMTPS profiles obtained for $\theta_{\mathrm{CO}} \approx 1$ also depend on $v_{\mathrm{m}}$ and $A_{\mathrm{m}}$ (Figs. $4 \mathrm{~b}-4 \mathrm{~d}$ ). For $v_{\mathrm{m}}=33 \mathrm{~V} / \mathrm{s}$ and $A_{\mathrm{m}}=20 \mathrm{mV}$, a net irreversible anodic current appears as a sharp peak at $0.94 \mathrm{~V}$, followed by a voltammetric contour from 1.0 to $1.45 \mathrm{~V}$ which is comparable to that already described in the absence of $\mathrm{CO}$. However, when $v_{\mathrm{m}}=100 \mathrm{~V} / \mathrm{s}$ and $A_{\mathrm{m}}=80 \mathrm{mV}$, an anodic current loop is observed as $v_{\mathrm{g}}$ moves in the positive direction. This loop, which is observed more clearly at relatively large values of $A_{\mathrm{m}}$, is directly related to the establishment of reversible reaction (1) once a fraction of the free $\mathrm{Pt}$ surface becomes available for this reaction.

For either $\theta_{C O}=0.52$ or $\theta_{C O}=1$, the backward shift of the voltammograms of each modulating cycle as the guide ramp progresses appears very clearly for large $A_{\mathrm{m}}$ values (Fig. 5). In this sense, the influence of $\theta_{60}$ in defining the shape of the voltammetric contour becomes relatively less important than either $A_{\mathrm{m}}$ or $v_{\mathrm{m}}$.

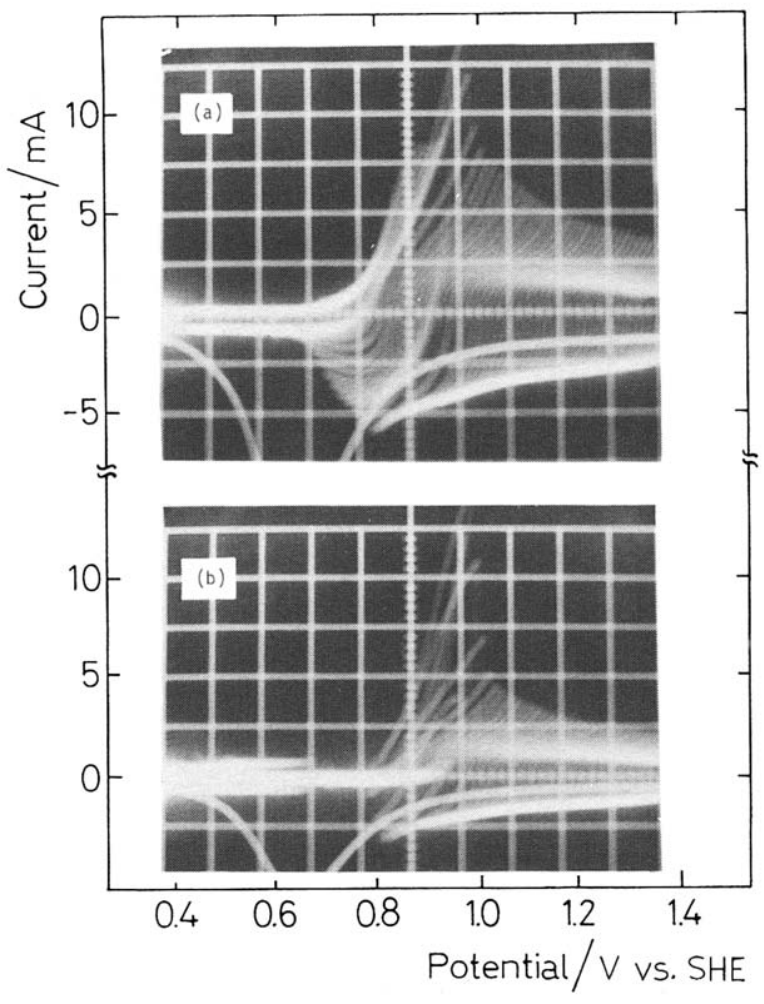

Fig. 5. TMTPS profiles obtained after adsorption of $\mathrm{CO}$ for $\theta_{\mathrm{CO}}=0.52$ (a) and $\theta_{\mathrm{CO}}=1$ (b). $v_{\mathrm{g}}=1 \mathrm{~V} / \mathrm{s}$, $A_{\mathrm{m}}=200 \mathrm{mV}$ and $v_{\mathrm{m}}=33 \mathrm{~V} / \mathrm{s}$. 


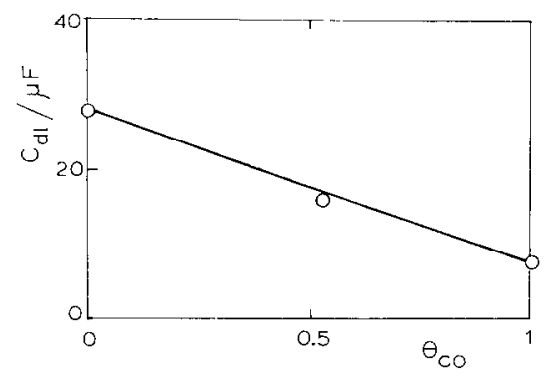

Fig 6. Dependence of the double-layer capacity on $\theta_{10}$. Geometric electrode area $=0.471 \mathrm{~cm}^{2}$.

Further interesting features of the TMTPS voltammetric profiles are also found in the electrical double-layer potential range. The value of the electrode capacitance estimated from the anodic to cathodic current gap in the $0.4-0.6 \mathrm{~V}$ range decreases linearly with $\theta_{(O)}$ (Fig. 6), and for a constant value of $\theta_{c}$, it is nearly independent of the frequency of the modulating signal in the $100-2500 \mathrm{~Hz}$ frequency range.

\section{DISCUSSION}

TMTPS fast voltammetry data related to the electrooxidation of CO preadsorbed on $\mathrm{Pt}$ indicate that the overall reaction under this condition consists of at least two different processes with the participation of various oxygen-containing species and forms of adsorbed $\mathrm{CO}$. Each reaction takes place within a definite potential range. These conclusions from TMTPS voltammetry werc cnvisaged earlier through conventional voltammetry [3,9]. The present data provide not only additional detailed information about the various reactions but also some quantitative data about the mean half-life time of the reacting species, as discussed below. For a rational discussion of the results it is convenient first to consider those obtained in the absence of adsorbed $\mathrm{CO}$, in order to distinguish the possible existence of weakly and strongly bound oxygen-containing species on polycrystalline $\mathrm{Pt}$, and second to consider their participation in an adsorbed reactant pair type mechanism in the electrooxidation reaction of adsorbed $\mathrm{CO}$.

\section{The reversible electroadsorption / electrodesorption of oxygen-containing species}

At low $A_{\mathrm{m}}$. TMTPS voltammetry shows at least three reversible pairs of peaks (Ia/Ic. IIa/IIc and IIIa/IIIc) (Fig. $2 \mathrm{a}$ ) in the $0.7-1.3 \mathrm{~V}$ range. As $A_{\mathrm{m}}$ increases, a change in the slope of each modulating cycle and the overlapping of peaks Ia and IIa are observed. Likewise, when the time spent durıng each modulating cycle $\left(A_{\mathrm{m}} / v_{\mathrm{m}}\right)$ is greater than $2.5 \times 10^{-4} \mathrm{~s}$, the reversible couple at ca. $0.98 \mathrm{~V}$ defined as peak $\mathrm{Ia} / \mathrm{IIa}$ is no longer detected.

The voltammetric peak multiplicity in the $0.8-1.0 \mathrm{~V}$ range can be assigned to distinguishable strongly bonded $(\mathrm{OH})$, and a weakly bonded $(\mathrm{OH})_{u}$ species on 
polycrystalline $\mathrm{Pt}$, as is the case for $\mathrm{H}$-adatom electroadsorption/electrodesorption [23-25]. From the present results and those reported earlier in the literature, one can conclude that the distribution of peaks Ia and IIa depends on the electrolyte composition in a way which, to some extent, is similar to that corresponding to $\mathrm{H}$ electroadsorption on polycrystalline $\mathrm{Pt}$. This suggests that the type of electroadsorbed species prevailing on a particular crystallographic plane is determined principally by the initial $\mathrm{H}_{2} \mathrm{O} / \mathrm{Pt}$ adsorption configuration [26-28].

On the other hand. the conjugated current peaks IIIa/IIIc are assigned to the reversible $\mathrm{O}$-electroadsorbed species [21]. The latter undergoes ageing processes under conventional low potential sweep rate voltammetry [21,22].

\section{The fast voltammetric electrooxidation of adsorhed $\mathrm{CO}$ on polycrystalline $\mathrm{Pt}$}

From previous work [9.13] it is known that two forms of adsorbed $\mathrm{CO}$ on $\mathrm{Pt}$ can be distinguished voltammetrically, namely, the bridge $(\mathrm{CO})_{B}$ and linear $(\mathrm{CO})_{L}$ forms. In conventional voltammetry these adsorbed $\mathrm{CO}$ species are electrooxidized in the 0.8-1.1 $\mathrm{V}$ range. The electrooxidation of both $\mathrm{CO}$ species is expressed by the following overall fast irreversible reaction:

$[\mathrm{Pt}]_{1}(\mathrm{CO})+\mathrm{Pt}(\mathrm{OH}) \rightarrow(x+1) \mathrm{Pt}+\mathrm{CO}_{2}+\mathrm{H}^{+}+e$

where $x=1$ for $(\mathrm{CO})_{\mathrm{L}}$ species and $x=2$ for $(\mathrm{CO})_{\mathrm{B}}$ species.

When the Pt surface is partially covered by adsorbed $\mathrm{CO}$ the electrooxidation reaction begins as soon as $\mathrm{Pt}(\mathrm{OH})$, is formed and immediately consumed through a two-adsorbed-species reaction (Figs. $4 \mathrm{a}$ and $4 \mathrm{~b}$ ). As $(\mathrm{CO})_{\mathrm{B}}$ is depleted, then the cathodic current contribution related to reaction (1) appears only when the potential of the guide ramp reaches that of the current peak associated with the electrooxidation of $(\mathrm{CO})_{B}$ (Fig. $\left.4 \mathrm{c}\right)$. This is direct evidence that $(\mathrm{CO})_{B}$ electrooxidation proceeds via $\mathrm{Pt}(\mathrm{OH})_{1}$, according to the reaction:

$\left[\mathrm{Pt}_{2}(\mathrm{CO})_{\mathrm{B}}+[\mathrm{Pt}](\mathrm{OH})_{-} \rightarrow[\mathrm{Pt}]_{2}+[\mathrm{Pt}]_{1}+\mathrm{CO}_{2}+\mathrm{H}^{+}+e^{-}\right.$

where the brackets denote reacting sites at the $\mathrm{Pt}$ surface and the parentheses indicate adsorbed species. Reaction (4) involving two adsorbed species is consistent with data from open-circuit measurements, where it was found that the open-circuit reduction of $\mathrm{Pt}(\mathrm{O})$ species is enhanced by the presence of adsorbed $\mathrm{CO}$ [29], and with gas phase results. where it was demonstrated that $\mathrm{O}$-adsorbed species cannot co-exist with adsorbed $\mathrm{CO}$ species unless $\theta_{C O}<0.03[30]$.

The cathodic pseudo-capacitance maximum. $\left(C_{\mathrm{ad}}\right)_{\mathrm{M}}=I_{\mathrm{Ic}} / v_{\mathrm{m}}$, reflects the capability of $(\mathrm{OH})$, species to follow the modulating signal. In order to evaluate the amount of adsorbed $\mathrm{OH}$ which is able to follow the potential modulation in the presence of adsorbed $\mathrm{CO},\left(C_{\mathrm{ad}}\right)_{\mathrm{M}}$ vs. $t_{\mathrm{m}}$ plots were considered. A linear $\left(C_{\mathrm{ad}}\right)_{\mathrm{M}}$ vs. In $t_{\mathrm{m}}$ relationship was found (Fig. 7) for both $\theta_{(O)}=0$ and $\theta_{(O)}=0.52$. The straight lines have different slopes but a common intersection point at $t_{\mathrm{n}}=1.1 \times 10^{-4} \mathrm{~s}$. The extrapolated value of $t_{\mathrm{m}}$ corresponding to $\left(C_{\mathrm{ad}}\right)_{\mathrm{m}}=0$ must be related to the minimum time to produce a detectable amount of adsorbed $(\mathrm{OH})$, species. The slope 


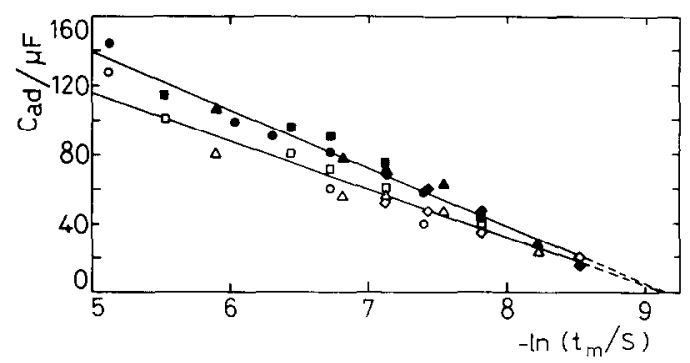

Fig 7. Maxımum adsorption pseudo-capacitance of peak Ic (calculated as $I_{\mathrm{k}} / \mathrm{v}_{\mathrm{m}}$ ) vs $t_{\mathrm{m}}=A_{\mathrm{m}} / \mathrm{v}_{\mathrm{m}}$ plotted for $\theta_{\mathrm{CO}}=0$ (filled symbols) and for $\theta_{\mathrm{c}(\mathrm{O}}=0.52$ (open symbols). $v_{\mathrm{m}}=33(0), 50(\square), 75(\diamond)$ and $100 \mathrm{~V} / \mathrm{s}(\Delta)$.

of the straight line varies inversely with the amount of adsorbed $\mathrm{CO}$, as expected for a chemical surface reaction consuming the intermediate which follows the potential modulation.

The TMTPS voltammograms run at $\theta_{C O}=0.52$ also show the electrooxidation of $(\mathrm{CO})_{\mathrm{L}}$ species in the potential range where the reversible couple assigned to peak $\mathrm{IIa} / \mathrm{IIc}$ in the blank is observed. This means that $(\mathrm{CO})_{\mathrm{L}}$ electrooxidation proceeds via $\mathrm{Pt}(\mathrm{OH})_{\mathrm{w}}$ intermediates according to the reaction:

$[\mathrm{Pt}](\mathrm{CO})_{\mathrm{L}}+[\mathrm{Pt}](\mathrm{OH})_{\mathrm{w}} \rightarrow[\mathrm{Pt}]+[\mathrm{Pt}]_{\mathrm{w}}+\mathrm{CO}_{2}+\mathrm{H}^{+}+e^{-}$

In this case, once the guide ramp exceeds the potential range of $(\mathrm{CO})_{\mathrm{L}}$ electrooxidation, the TMTPS becomes coincident with that of the blank unless $A_{\mathrm{m}}$ is sufficiently large to detect reaction (1) occurring at low overpotentials.

The TMTPS voltammetric response for $\theta_{C O}=1$ indicates that a single $\mathrm{CO}$ adsorbed species, namely $(\mathrm{CO})_{\mathrm{L}}$, participates in the initial reaction. In this case, a large overpotential is required to start $\mathrm{CO}$ electrooxidation since there are probably very few $\mathrm{Pt}$ sites available for $\mathrm{Pt}(\mathrm{OH})$ formation. It is probable that the initial reaction proceeds via a denucleation mechanism, that is, once a single $\mathrm{Pt}(\mathrm{OH})$ is formed it reacts with the nearest $(\mathrm{CO})_{L}$ according to reaction (5), hence creating two free $\mathrm{Pt}$ sites, which in turn are able to form $(\mathrm{OH})$ species.

No evidence of adsorbed CO conversion from the B form to the $\mathrm{L}$ form as the reaction proceeds is noticed. This reaction appears as a very slow process in the time scale of the present experiments in agreement with results reported earlier [9].

It is also clear that the presence of adsorbed $\mathrm{CO}$ decreases the capacity $\left(C_{\mathrm{dl}}\right)$ of the electrical double layer considerably. This change can be exclusively assigned to the inner part of the double layer structure. Provided that the values of $C_{\mathrm{dl}}$, which appear to be almost independent of the applied potential in the $0.38-0.65 \mathrm{~V}$ range, are given by the equation $C_{\mathrm{dl}}=\epsilon_{0} / 4 \pi d$ (where $\epsilon_{0}$ is the dielectric constant at the inner part of the double layer, and $d$ corresponds to the distance between the planes defining the condenser associated with it), the decrease in $C_{\mathrm{dl}}$ can be assigned either to a decrease in $\epsilon_{0}$ or an increase in $d$. The constant capacity observed for a constant $\theta_{\mathrm{CO}}$ value at frequencies greater than $100 \mathrm{~Hz}$ suggests that the dependence of $C_{\mathrm{d} 1}$ on $\theta_{\mathrm{CO}}$ is probably related to changes in $\epsilon_{0}$. 
In conclusion, TMTPS voltammetry applied to the electrooxidation of CO previously adsorbed on polycrystalline $\mathrm{Pt}$ in acid shows that the first stage in the electrooxidation process requires $\mathrm{OH}$ electroformation from water. Two adsorbed states of $\mathrm{OH}$ species related to the configurations of the water molecules at the various crystallographic planes of $\mathrm{Pt}$ participate in the overall reaction. Depending on the value of $\theta_{\mathrm{cO}}$, two different forms of adsorbed $\mathrm{CO}$ must also be considered in the electrooxidation process. Therefore, reactions between strongly and weakly bonded adsorbed $\mathrm{OH}$ with the linear and the bridge forms of adsorbed $\mathrm{CO}$ are distinguished voltammetrically. These results confirm the previous finding on the mechanism of the voltammetric electrooxidation of adsorbed $\mathrm{CO}$ in the absence of readsorption of $\mathrm{CO}$ from the solution, and contribute to an understanding of the initial large anodic polarization of the reaction.

\section{ACKNOWLEDGEMENTS}

INIFTA is a Research Institute jointly established by the Universidad Nacional de La Plata, the Consejo Nacional de Investigaciones Cientificas y Técnicas and the Comisión de Investigaciones Científicas de la Provincia de Buenos Aires. This work was partially supported by the Regional Program for the Scientific and Technological Development of the Organization of the American States. Part of the equipment used in the present work was provided through the Cooperation Agreement between the University of Mainz (Germany) and the University of La Plata (Argentina).

\section{REFERENCES}

1 J.P. Randın in A.J. Bard (Ed.), The Encyclopedıa of Electrochemistry of the Elements, Vol. 7, Marcel Dekker, New York, 1979, Ch. 1.

2 M.W. Bretter in J.O'M. Bockrıs and B.E. Conway (Eds.). Modern Aspects of Electrochemistry, Vol. 10, Plenum Press, New York, 1979, Ch. 3.

3 S. Gilman, J. Phys Chem.. 66 (1962) 2657; 67 (1963) 78, 1898; 68 (1964) 70.

4 P. Stonehart. Electrochum. Acta, 17 (1972) 369; 18 (1973) 63.

5 C MacCallum and D. Pletcher, J. Electroanal. Chem., 70 (1976) 277

6 K F. Blurton and J.M. Sedlak, J. Electrochem. Soc., 121 (1974) 1315.

7 A. Czerwiñski and J. Sobkowskı, J. Electroanal. Chem., 91 (1978) 47.

8 M.W. Breiter, J. Electroanal. Chem., 65 (1975) 623; 101 (1979) 329; 127 (1981) 157; 180 (1984) 25.

9 S.A. Bilmes, N.R. de Tacconı and A.J. Arvia, J. Electroanal. Chem., 164 (1984) 129.

10 P. Stonehart, J. Electroanal. Chem., 15 (1967) 239.

11 C. Lamy, J.M. Leger, J. Clavilier and R. Parsons, J. Electroanal. Chem., 150 (1983) 71

12 J.M. Leger, B. Beden, C. Lamy and S. B1lmes. J. Electroanal. Chem.. 170 (1984) 305.

13 S.A. Bilmes, N R. de Tacconı and A.J. Arvia, An. Asoc. Quim Argent., in press.

14 B.V. Tilak, B.E. Conway and H. Angersteın-Kozlowska. J. Electroanal. Chem., 48 (1973) 1.

15 H. Angersteın-Kozlowska, B.E. Conway, B. Barnett and J. Mozota, J. Electroanal. Chem., 100 (1979) 417.

16 B. Beden, A. Bewick, K. Kunimatsu and C. Lamy, J. Electroanal. Chem., 142 (1982) 345.

17 N. Collas, B. Beden, J.M. Leger and C. Lamy, J. Electroanal. Chem., 186 (1985) 287.

18 B.E. Conway, H. Angerstenn-Kozlowska, F.C. Ho, J. Klinger. M. MacDougall and S. Gottesfeld, Discuss. Faraday Soc, 56 (1973) 210. 
19 N.R. de Tacconı, J.O. Zerbino and A.J. Arvia, J. Electroanal. Chem., 79 (1977) 287.

20 N.R. de Tacconi. A.J. Calandra and A J. Arvia. J Electroanal. Chem., 57 (1974) 267.

21 A.J. Arvia, Isr. J. Chem., 18 (1979) 89.

22 M.E. Folquer, J.O. Zerbıno, N.R. de Tacconı and A.J. Arvı. J. Electrochem. Soc., 126 (1979) 592.

23 H. Angersteın-Kozlowska. W.B.A. Sharp and B.E. Conway in M.W. Breiter (Ed), Electrocatalysis, Softbound Proceedings Series, The Electrochemical Society. Princeton. NJ, 1974, p. 94.

24 P.N. Ross, J. Electroanal. Chem, 76 (1977) 139.

25 B.H. Loo and T.E. Furtak. Electrochim. Acta, 25 (1980) 505

26 R. Parsons, J. Electroanal. Chem., 59 (1975) 229.

27 J. Clavilier, D. Armand and B L. Wu. J. Electroanal. Chem., 135 (1982) 159

28 S Trasattı, Electrochım. Acta, 28 (1983) 1093

29 S.A. Bılmes, N.R. de Tacconı and A.J. Arvia. J. Electroanal. Chem., 117 (1984) 201.

30 P.R. Norton, D.K. Creber and J.W. Goodale in G. Ertl (Ed.), Proc. 4th Int. Conf, on Solıd Surf., and 3rd Eur. Conf. on Surf. Sci., Cannes. 1980, supplement to Vide Couches Minces, 201 (1981) 390. 